\title{
High capacity yielding bolt support for rockburst prone workings
}

\author{
J. Oldsen Jennmar Corporation, USA \\ T. Roberts Jennmar Australia Pty Ltd, Australia
}

\begin{abstract}
Rockbursts are one of the greatest challenges to ground control in the mining industry. The general principle of ground control in rockburst prone conditions is to transfer the dynamic energy of a rockburst event to the yielding support system to facilitate absorption and controlled deformation of rock mass while containing materials, or helping the rock mass to support itself. Jennmar research and development has resulted in a technically reliable and effective yielding rockbolt. The first generation Yield-Lok bolt accepted 150-250 mm of deflection at 8-10 t loads for every $16.4 \mathrm{~kJ}$ energy input. The bolt is made of $17.2 \mathrm{~mm}$ diameter, Grade 75 round steel bar. The steel bar is upset to specified dimensions at one end and partially or fully encapsulated in an engineered polymer coating to achieve designed yielding performance under dynamic loading. The bolt is tensioned and provides immediate primary support on installation. In low energy, dead weight loading conditions, the Yield-Lok bolt performs similarly to a rebar bolt, providing stiff reinforcement and containment of the rock mass. In high energy loading conditions, the upset transfers the impacts on the surrounding polymer coating and energy is dissipated by ploughing the upset through the polymer.
\end{abstract}

Recent laboratory tests have shown greater loads with reduced deflection. The results were repeatable and uniformly consistent. The bolt is made of $17.2 \mathrm{~mm}$ diameter, Grade 100 round steel bar. The steel bar is upset to specified dimensions at one end and partially or fully encapsulated in an engineered polymer coating to achieve designed yielding performance under dynamic loading.

Higher energy designs have also been successfully tested. The bolt is manufactured from $23.1 \mathrm{~mm}$ diameter, Grade 75 round steel bar. The steel bar is upset to specified dimensions at one end and partially or fully encapsulated in an engineered polymer coating to achieve designed yielding performance under dynamic loading. In static loading this bolt approaches $30 \mathrm{t}$ tensile loads and has the associated higher shear load available.

\section{Introduction of the Yield-Lok bolt}

The Yield-Lok bolt (WIPO, 2011) was developed by Jennmar of Canada for ground support in rock prone to seismic burst conditions (Wu and Oldsen, 2010). When exposed to high energy impact loading, standard bolts fail in tension or pull through end support plates. Previous yield bolt designs attempted to employ either low strength grouts or metallic deformation to dissipate seismic energy.

Weak grout systems are hampered by the inherent difficulty in maintaining the required grout pull-out resistance. If the grout is too strong, the bolt fails in tension. If the grout is too weak, the bolts can be pulled out at a fraction of their tensile strength. Metallic deformation designs offer more predicable yield, but are complicated and expensive.

As illustrated in Figure 1, the Yield-Lok bolt is made from round steel bar upset to specified dimensions at one end and partially or fully encapsulated in an engineered polymer coating to achieve designed yielding performance under high energy loading. In the new generation Yield-Lok, under quasi-static loading conditions, the design of the upset and the engineered polymer can produce a rebar bolt performance or a stick-slip response similar to a Friction-Lok bolt, depending on the ground response desired. The new generation also incorporates a $23 \mathrm{~mm}$ diameter bolt of higher strength. Resin mixing and hole centring paddles, longitudinally spaced over the length of the coating, provide shredding of the resin cartridge 
packaging and aid in the centring of the bolt in the borehole. The other end of the bar is threaded for tensioning with a nut. A dome plate and spherical washer are used for angle compensation and to load the bolt axially. The bolt is tensioned and provides immediate primary support on installation. Under high energy loading conditions, the upset transfers the impact load on the surrounding polymer coating, resulting in confined compression, thermal softening, and flow of the polymer around the upset, which creates the desired ploughing effect. The energy is therefore dissipated by pulling or ploughing the upset through the polymer. Part of the dynamic energy is also consumed in the friction between the smooth bar and the polymer coating.

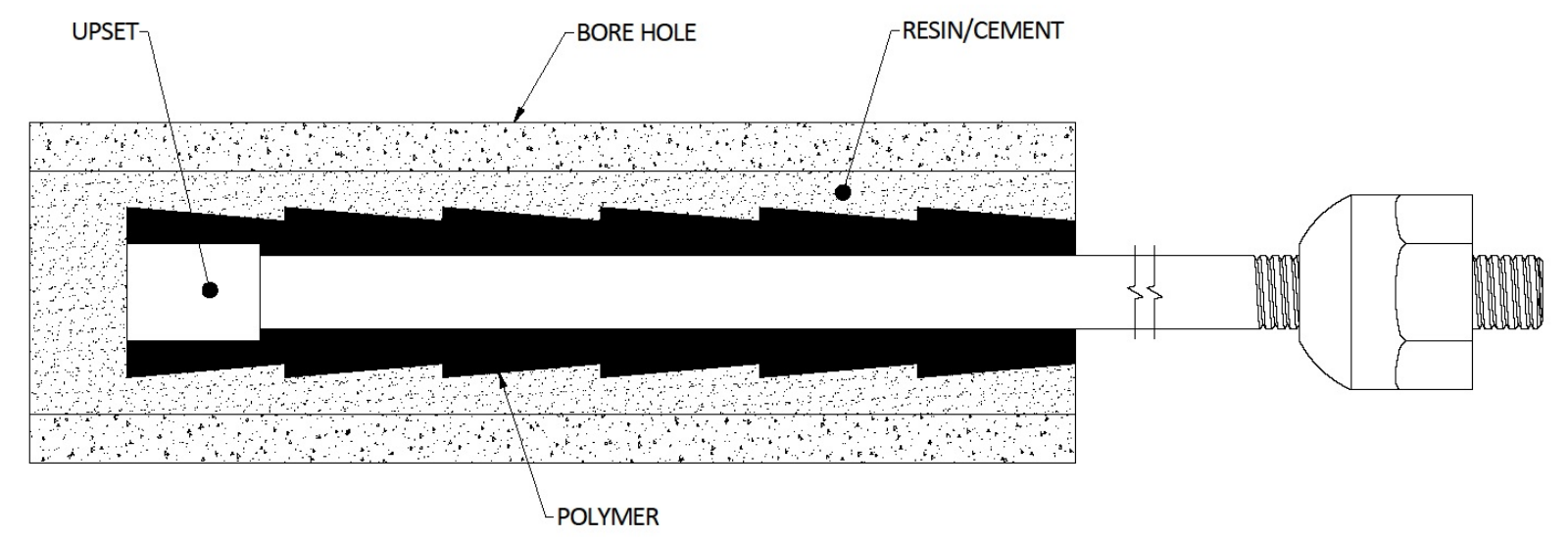

Figure 1 Yield-Lok bolt engineered yielding mechanism

\section{Quasi-static performance of the Yield-Lok bolt}

Under low energy (dead weight) loading conditions, Yield-Lok bolts can perform similar to a point-anchored rebar bolt, providing stiff reinforcement and containment of the rock mass. The wall of the drill hole with the resin provides confinement to the polymer, producing anchorage against the upset. Figure 2 summarises results of a series of mine pull tests conducted with Yield-Lok bolts installed in a $36 \mathrm{~mm}$ borehole with fully encapsulated resin. The samples consistently yielded the nominal steel yielding strength of $14 \mathrm{t}$. 


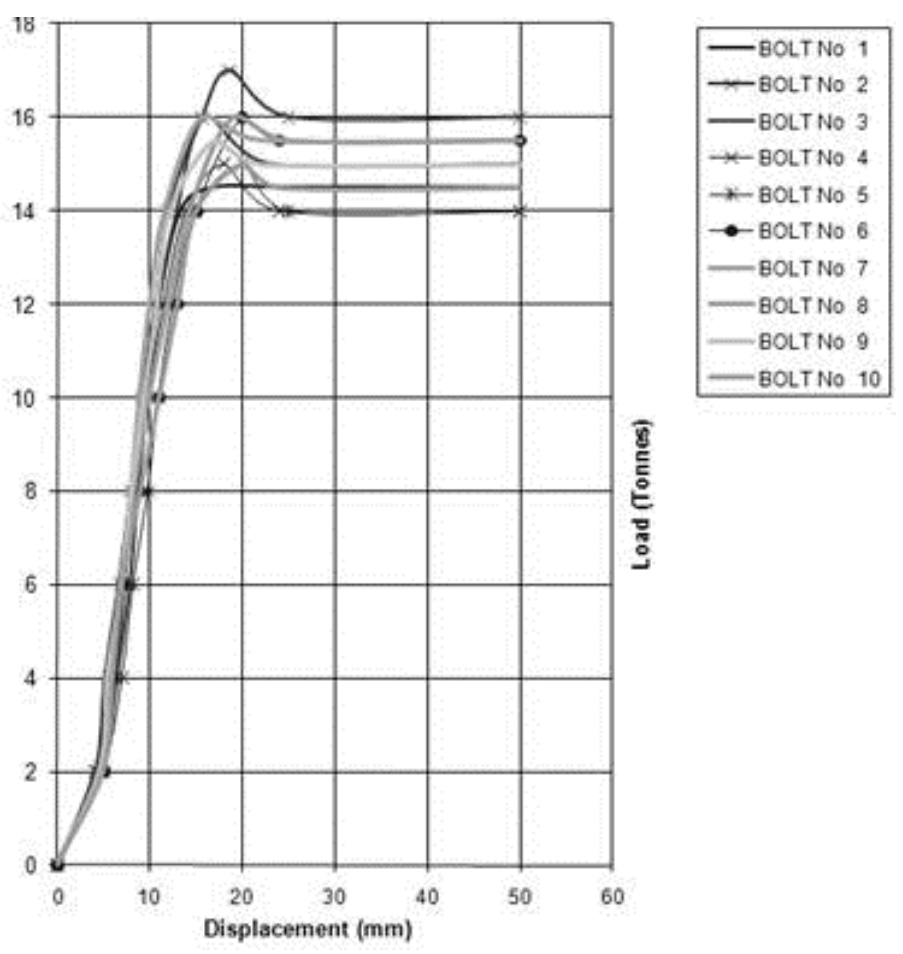

Figure 2 Series of pull tests conducted at Perilya mine with Yield-Lok bolts installed in a $36 \mathrm{~mm}$ borehole fully encapsulated by JLok resin

Static pull tests performed at CANMET used the direct quasi-static test method with a continuous tube and standard pull test on the bolt end. Figure 3 is a drawing of the pull test set-up.

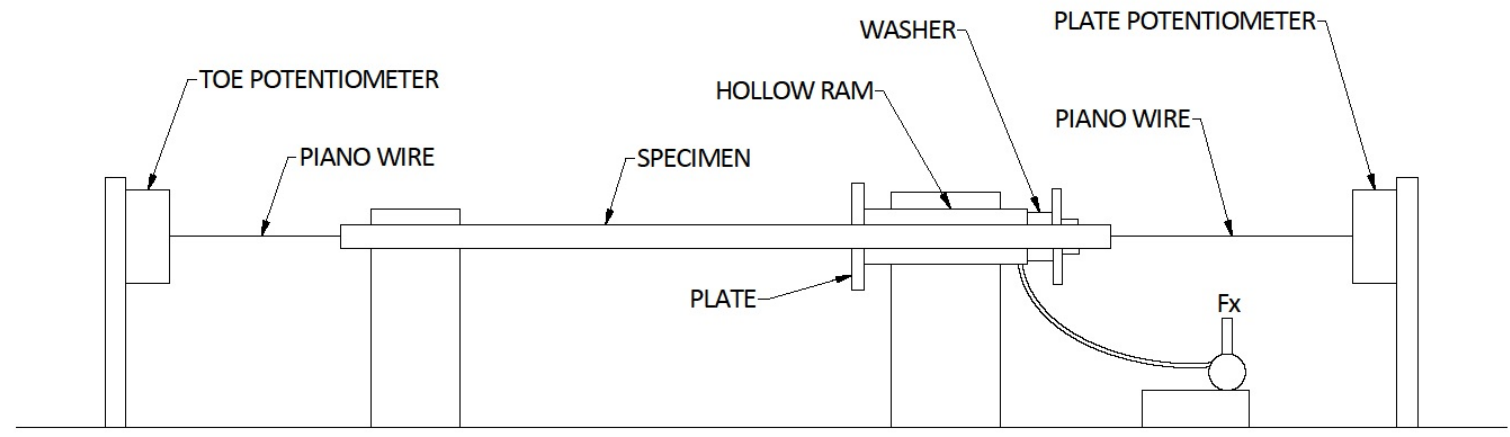

Figure 3 A drawing of the pull test set-up

Static pull tests performed at CANMET more fully demonstrates the performance of the bolt/upset/ polymer in various combinations as shown in Table 1 . The $17.2 \mathrm{~mm}$ bolts were installed in a rifled $35 \mathrm{~mm}$ diameter borehole. The upsets ranged from just over $21 \mathrm{~mm}$ (U1) to just under $24 \mathrm{~mm}$ (U2) for the $17.2 \mathrm{~mm}$ bolt. The $23 \mathrm{~mm}$ bolts were installed in a rifled $38 \mathrm{~mm}$ borehole. The upsets ranged from just over $28 \mathrm{~mm}$ (U3) to just under $30 \mathrm{~mm}$ (U4). The coating has increasing stiffness with C1 being lowest and C3 being highest. C2 was approximately halfway between C1 and C3. Some bolts were installed in J-LOK polyester mine resin and some were installed in cement. No difference in performance was noted between resin and grout. 
Table 1 CANMET static pull tests

\begin{tabular}{|c|c|c|c|c|c|c|c|c|c|c|c|c|}
\hline$\stackrel{\breve{y}}{⺊}$ & $\begin{array}{l}\text { 苛 } \\
\text { ㄴํㄴ }\end{array}$ & $\begin{array}{l}\frac{0}{0} \\
\frac{0}{0} \\
\text { (psi) }\end{array}$ & $\begin{array}{c}\stackrel{N}{N} \\
\frac{N}{\pi} \\
\infty \\
(\mathrm{mm})\end{array}$ & 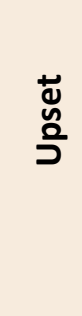 & 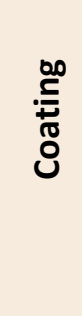 & 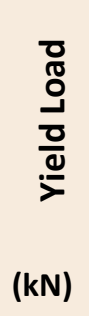 & 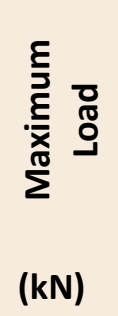 & 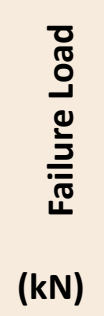 & 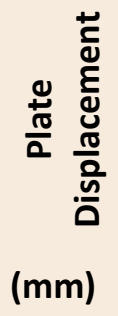 & 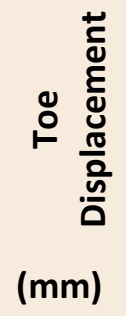 & 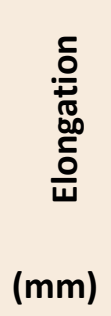 & 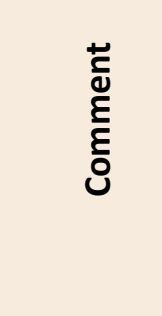 \\
\hline 2 & Resin & 75 & 17.2 & U1 & $\mathrm{C} 1$ & 144 & 151 & - & 264 & 247 & 17 & Stick/Slip \\
\hline 3 & Cement & 100 & 17.2 & U2 & C2 & 147 & 185 & 172 & 119 & 47 & 72 & Broke \\
\hline 3 & Cement & 100 & 17.2 & U2 & C3 & 148 & 195 & 163 & 125 & 26 & 99 & Broke \\
\hline 1 & Resin & 75 & 23 & U3 & $\mathrm{C} 2$ & 210 & 260 & - & 256 & 221 & 35 & Stick/Slip \\
\hline 1 & Resin & 75 & 23 & U4 & $\mathrm{C} 2$ & 188 & 302 & 255 & 237 & 172 & 65 & Broke \\
\hline 1 & Resin & 75 & 23 & U3 & C3 & 191 & 350 & 322 & 147 & 42 & 105 & Broke \\
\hline 1 & Resin & 75 & 23 & U4 & C3 & 200 & 345 & 340 & 140 & 32 & 108 & Broke \\
\hline
\end{tabular}

By modifying the upset diameter and stiffness of the polymer coating, the load versus displacement can be adjusted to accommodate significant movement in squeezing ground. Conversely, if the static performance of a fully grouted rebar is desired, the load versus displacement can be made similar to a straight rebar pull. Load and displacement data from selected pull tests are shown in Figures 4, 5, 6, and 7.

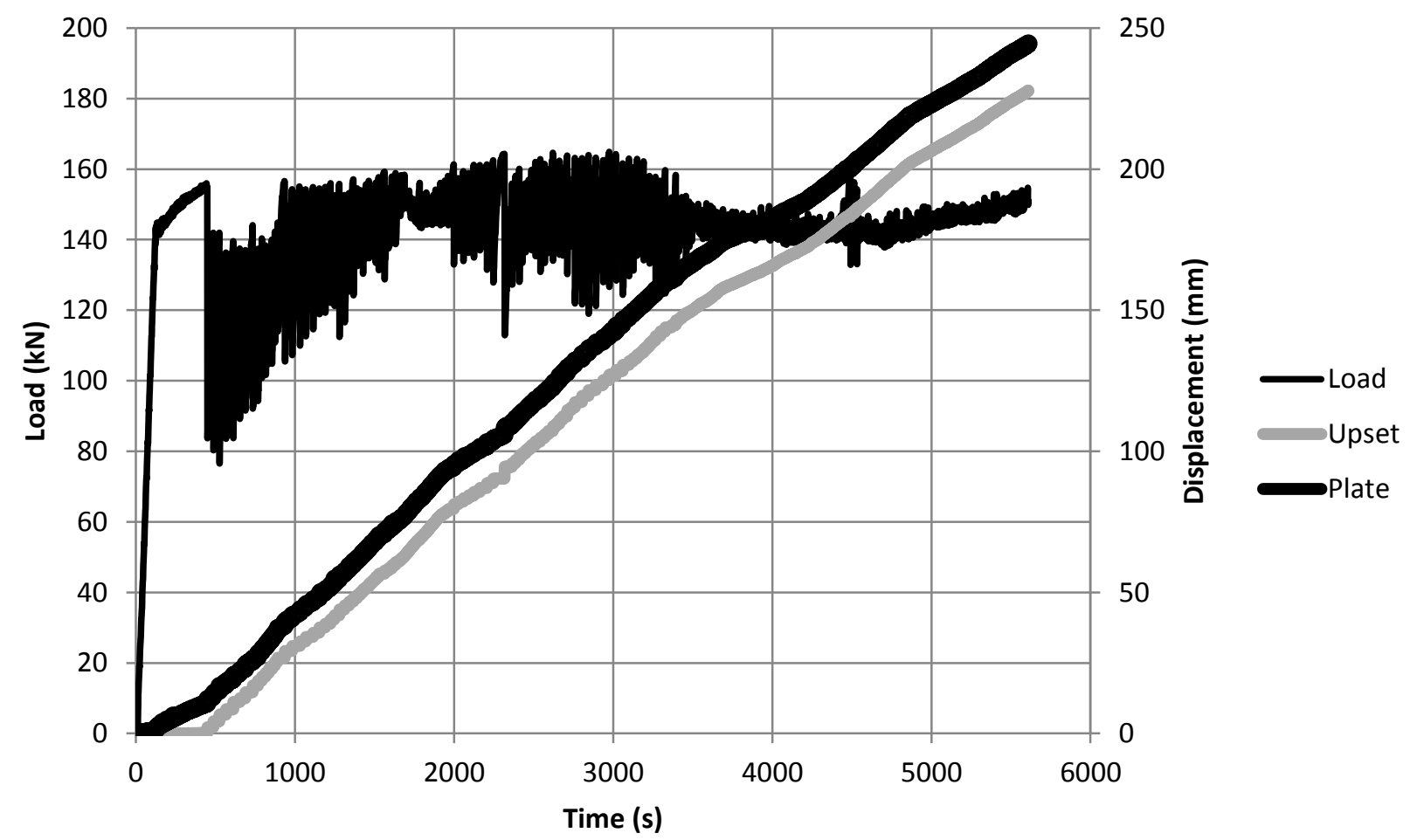

Figure 4 Pull test of $17.2 \mathrm{~mm}, \mathrm{U}_{1}, \mathrm{C}_{1}$ bolt

Figure 4 is the pull test showing Stick/Slip for the $17.2 \mathrm{~mm}$ bolt. At a load of $144 \mathrm{kN}$, the upset pulled through the polymer coating a total length of $228 \mathrm{~mm}$. Plate movement totalled $244 \mathrm{~mm}$, resulting in a bolt stretch of $16 \mathrm{~mm}$. 


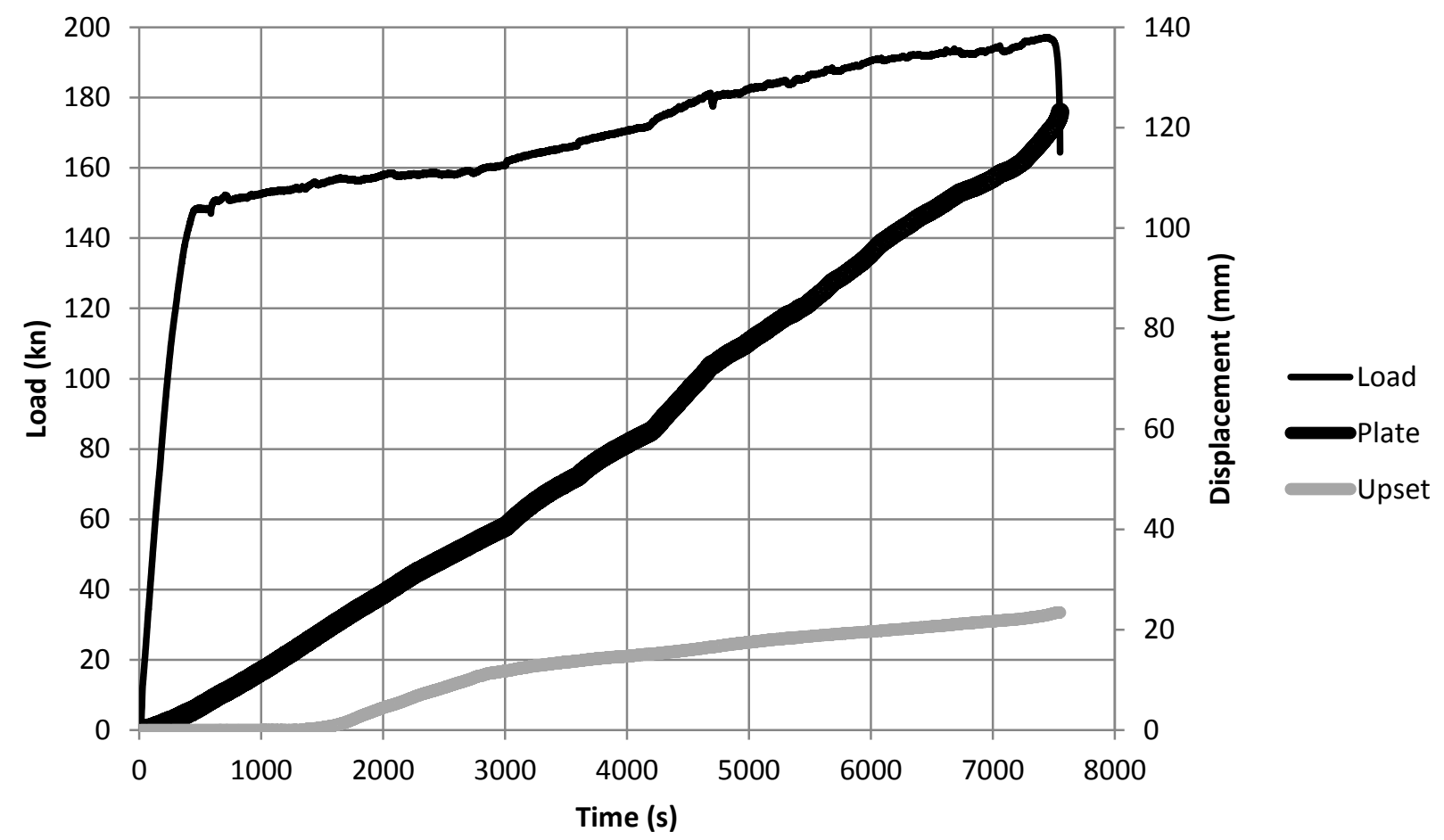

Figure 5 Pull test of $17.2 \mathrm{~mm} \mathrm{U}, \mathrm{C}_{3}$ bolt

Figure 5 is the pull test showing rebar like support which produced a tensile break of the $17.2 \mathrm{~mm}$ bolt. At a load of approximately $150 \mathrm{kN}$, the bolt went into yield and continued to load to $195 \mathrm{kN}$. Plate movement totalled $120 \mathrm{~mm}$, with the upset moving a total of $25 \mathrm{~mm}$ resulting in a bolt stretch of $95 \mathrm{~mm}$. At this point the bolt broke.

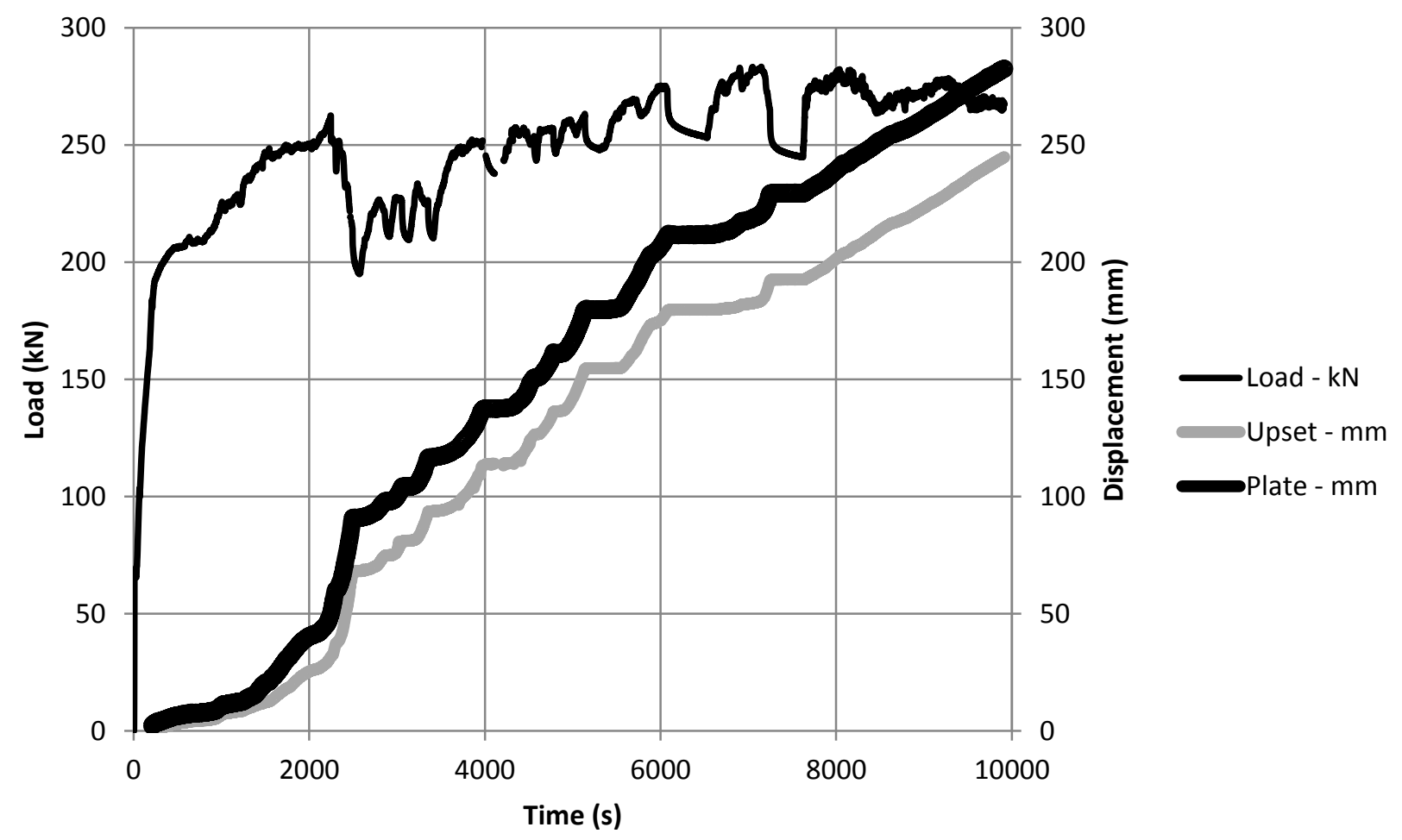

Figure 6 Pull test of $23 \mathrm{~mm} U_{3}, C_{2}$ bolt 
Figure 6 is the pull test showing Stick/Slip for the $23 \mathrm{~mm}$ bolt. At a load of $241 \mathrm{kN}$, the upset pulled through the polymer coating a total length of $221 \mathrm{~mm}$. Plate movement totalled $256 \mathrm{~mm}$, resulting in a bolt stretch of $35 \mathrm{~mm}$.

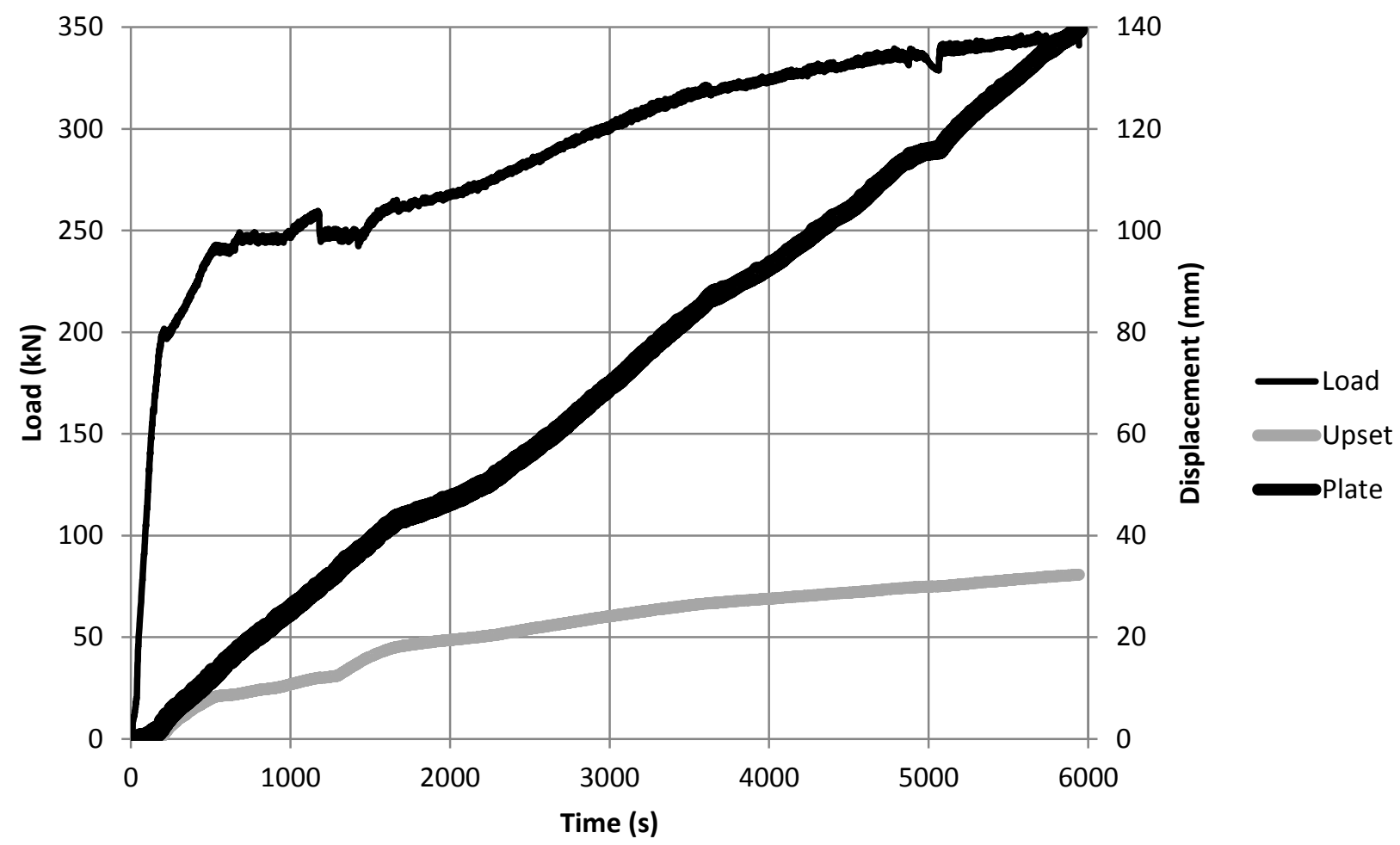

Figure 7 Pull test of $23 \mathrm{~mm} \mathrm{U}_{4}, \mathrm{C}_{3}$ bolt

Figure 7 is the pull test showing rebar like support which produced a tensile break of the $23 \mathrm{~mm}$ bolt. At a load of approximately $200 \mathrm{kN}$, the bolt began yield, increasing the load to $345 \mathrm{kN}$. Plate movement totalled $140 \mathrm{~mm}$, with the upset moving a total of $32 \mathrm{~mm}$ resulting in a bolt stretch of $108 \mathrm{~mm}$. At this point the bolt broke.

\section{Dynamic performance of the Yield-Lok}

A number of dynamic drop tests were conducted at the CANMET test facility in Ottawa, Canada, to test the high energy performance of the Yield-Lok bolts.

The drop test method simulated a high energy load condition similar in amplitude and velocity to a rockburst event. This test protocol has been established as a bench mark test used in the development of other types of yielding supports (ASTM D7401-08 (2008)). The direct dynamic impact test method was used. This employed a continuous tube with the weight impacting the bolt end. Boreholes were simulated by $12 \mathrm{~mm}$ wall steel tubes with an internal diameter of $35 \mathrm{~mm}$ for the $17.2 \mathrm{~mm}$ bolts and $38 \mathrm{~mm}$ for the $23.1 \mathrm{~mm}$ bolts. The steel tube preparation included a slight roughening of the inside surface over approximately the last meter. This roughened section was referred to as the top of the tube where the bolt is resin grouted or cement grouted.

The standard practice for installation in cement and resin was followed. No differences in performance were noted. CANMET personnel commented that previous testing of a wide range of dynamic bolts saw no differences in performance between cement and resin.

Drop tests were conducted in the drop test rig of 3 tonne capacity and $2 \mathrm{~m}$ height (Figure 9). As recommended in the ASTM standard for dynamic tests (ASTM D7401-08 (2008)), a drop weight of 1,115 kg and drop height of $1.5 \mathrm{~m}$ were used to produce the loading velocity of $5.4 \mathrm{~m} / \mathrm{s}$ and an input energy of 
$16.4 \mathrm{~kJ}$. A drop weight of 2,006 $\mathrm{kg}$ and drop height of $1.5 \mathrm{~m}$ were used to produce the loading velocity of $5.4 \mathrm{~m} / \mathrm{s}$ and an input energy of $29.5 \mathrm{~kJ}$. A drop weight of 2,897 kg and drop height of $1.5 \mathrm{~m}$ were used to produce the loading velocity of $5.4 \mathrm{~m} / \mathrm{s}$ and an input energy of $42.6 \mathrm{~kJ}$. A drop weight of 2,897 $\mathrm{kg}$ and drop height of $1.8 \mathrm{~m}$ were used to produce the loading velocity of $5.9 \mathrm{~m} / \mathrm{s}$ and an input energy of $51.2 \mathrm{~kJ}$. This last input energy of $51.2 \mathrm{~kJ}$ used a greater height and velocity that the other three energy input states because the maximum test weight of $2,897 \mathrm{~kg}$ had been reached.

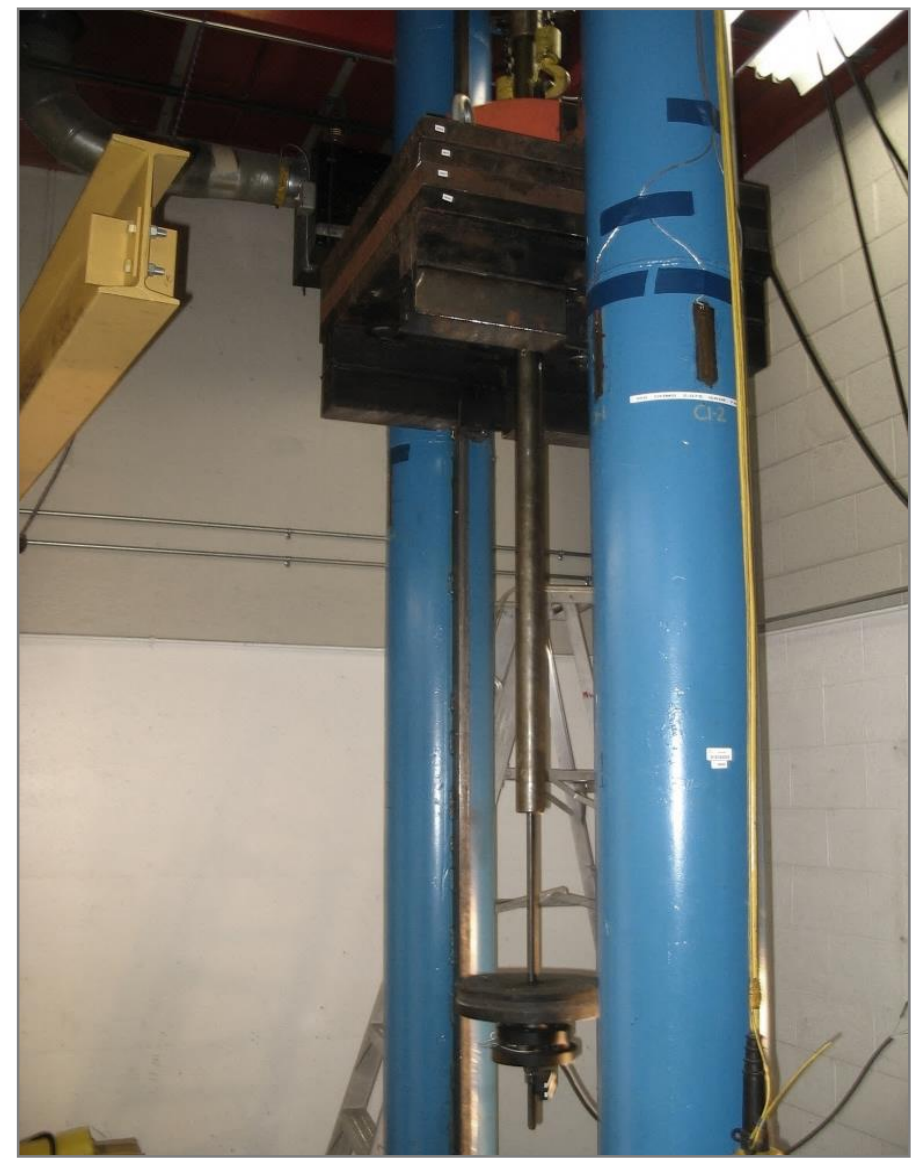

\section{Figure 8 Dynamic testing rig}

Test results from standard energy input and various energy inputs are summarised in Table 2. Most of the input dynamic energy is consumed when the upset ploughs through the polymer, while a small percentage of the energy is consumed in steel elongation.

Typical first drop test results are presented in Figure 10. Generally, for a given bar size and upset, an increase in coating stiffness produces a reduction in displacement but greater bolt strain. Changes in the upset for a given bar size does not appear to affect the displacement significantly. In most cases, at least two drops of the same energy were applied to the bolt in succession without failure. 
Table 2 Dynamic drop test results

\begin{tabular}{|c|c|c|c|c|c|c|}
\hline $\begin{array}{l}\text { Input Energy } \\
\text { (kJ) }\end{array}$ & $\begin{array}{c}\text { Bar Size } \\
(\mathrm{mm})\end{array}$ & Upset & Coating & $\begin{array}{l}\text { Displacement } \\
(\mathrm{mm})\end{array}$ & $\begin{array}{l}\text { Steel Stretch } \\
\qquad(\mathrm{mm})\end{array}$ & $\begin{array}{l}\text { Absorbed Energy } \\
\text { (kJ) }\end{array}$ \\
\hline \multirow[t]{4}{*}{16.7} & 17.2 & U1 & $\mathrm{C} 1$ & 203 & 2 & N/A \\
\hline & & U2 & C1 & 186 & 6 & 17 \\
\hline & & & $\mathrm{C} 2$ & 127 & 24 & 15 \\
\hline & & & C3 & 110 & 33 & 14 \\
\hline \multirow[t]{6}{*}{29.5} & 17.2 & U2 & C2 & 291 & 5 & 24 \\
\hline & & & C3 & 262 & 33 & 33 \\
\hline & 23 & U3 & $\mathrm{C} 2$ & 172 & 12 & 30 \\
\hline & & & C3 & 166 & 6 & 32 \\
\hline & & U4 & C2 & 162 & 5 & 29 \\
\hline & & & C3 & 149 & 8 & 28 \\
\hline \multirow[t]{4}{*}{42.6} & 17.2 & U2 & C2 & 493 & 9 & 52 \\
\hline & & & C3 & 515 & 27 & 56 \\
\hline & 23 & U3 & C2 & 352 & 5 & 53 \\
\hline & & U4 & C2 & 271 & 6 & 50 \\
\hline \multirow[t]{2}{*}{51.2} & 23 & U3 & C2 & 376 & 5 & 62 \\
\hline & & U4 & C2 & 373 & 1 & 62 \\
\hline
\end{tabular}

Typical load versus displacement and absorbed energy graphs, Figures 9, 10, and 11, are shown overleaf for the $23 \mathrm{~mm}$ bolt. All bolt graphs shown had the U3 upset and C2 coating. These are first drop responses for impact energies of $29.5,42.6$, and $51.2 \mathrm{~kJ}$. In all cases, the absorbed energy was greater than the impact energy. The desired goal performance of the Yield-Lok bolt, less than $250 \mathrm{~mm}$ of movement with an impact of $30 \mathrm{~kJ}$, was achieved. 


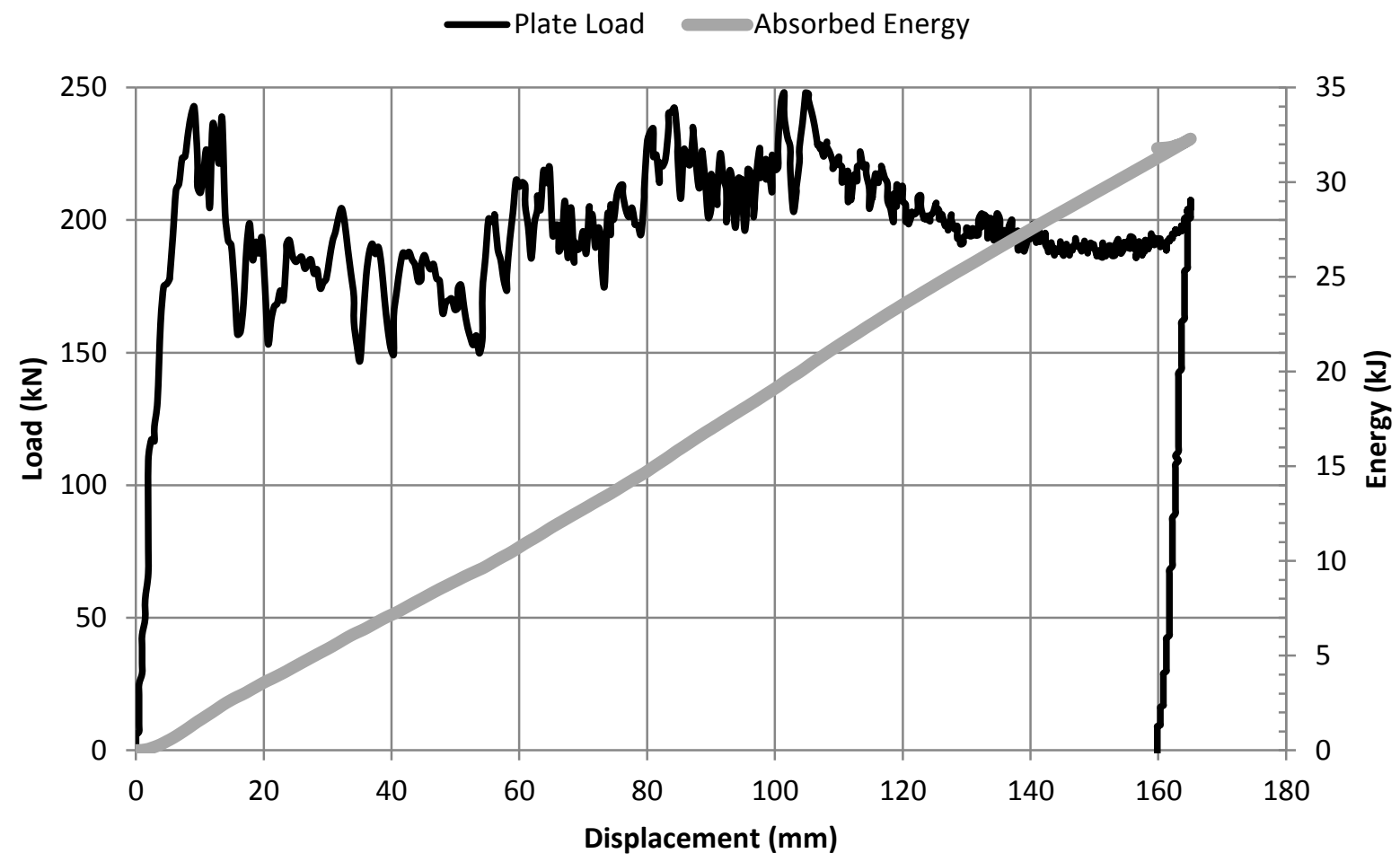

Figure $929.5 \mathrm{~kJ}$ dynamic drop test, $23 \mathrm{~mm}$ bolt, $U_{3}$ upset, $C_{2}$ coating

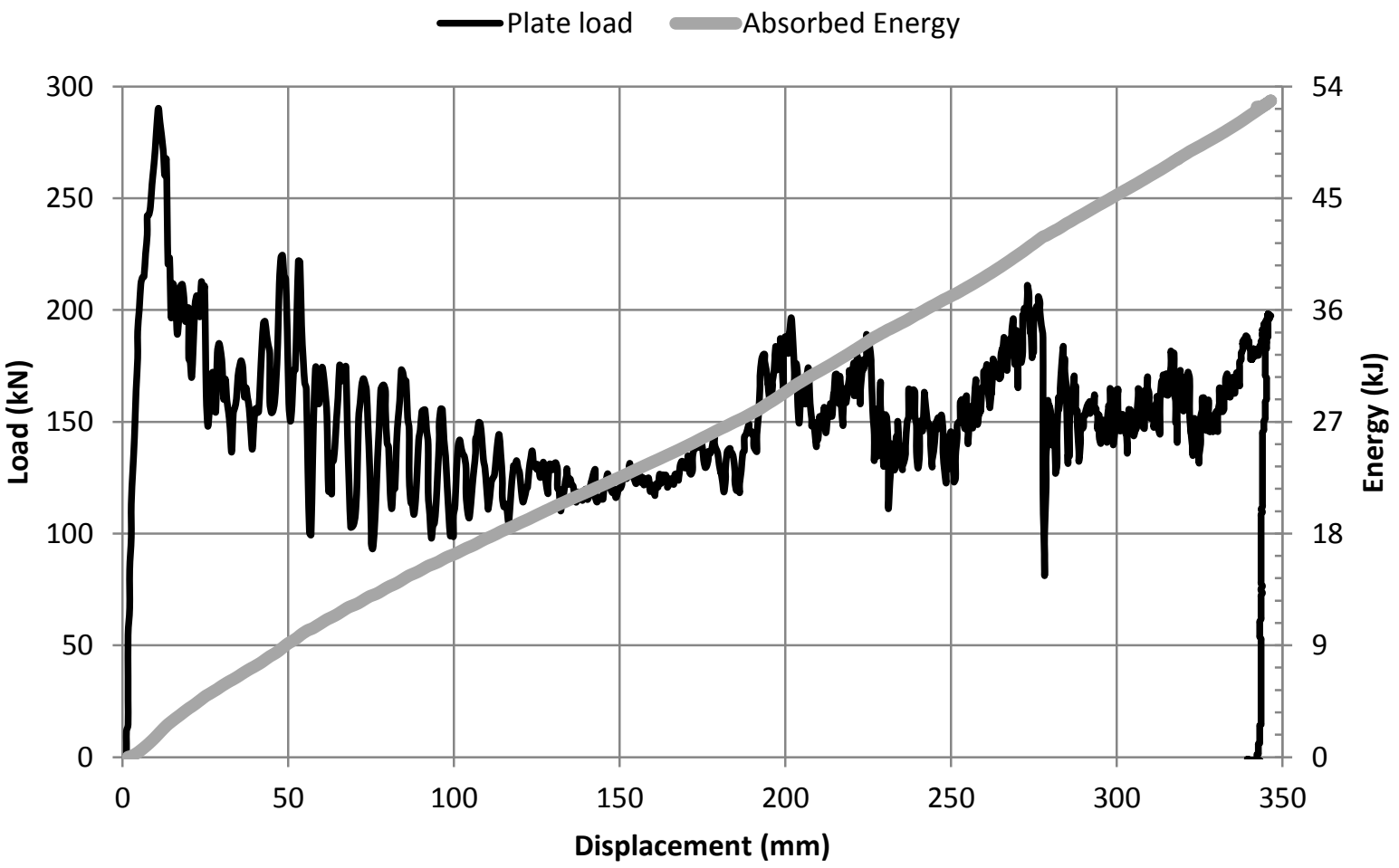

Figure $1042.6 \mathrm{~kJ}$ dynamic drop test, 23mm bolt, $U_{3}$ upset, $C_{2}$ coating 


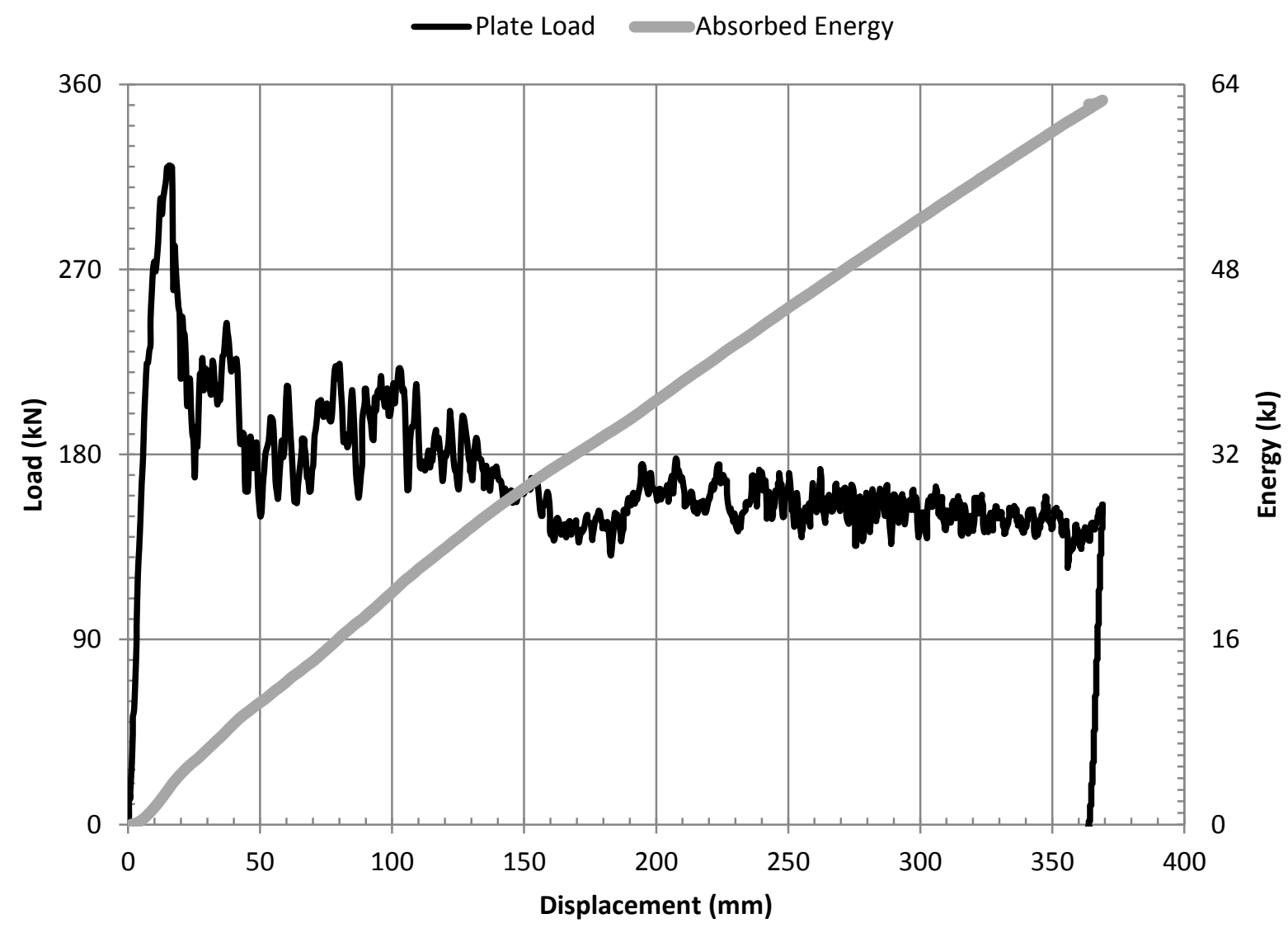

Figure $1151.2 \mathrm{~kJ}$ dynamic drop test, $23 \mathrm{~mm}$ bolt, $\mathrm{U}_{3}$ upset, $\mathrm{C}_{2}$ coating

\section{$4 \quad$ Conclusions}

Based on the scouting tests performed at CANMET, a medium or high strength dynamic Yield-Lok bolt can be produced for given mine design conditions. In addition to the dynamic response of the Yield-Lok bolt, static loading conditions can be tailored for stiff static response or a yielding static response for squeezing ground conditions. A graph of dynamic test results is shown in Figure 12. Parts of this graph are taken from the CANMET "Technical Information Data Sheets" (Doucet and Voyzelle, 2012). The black dotted line represents the average response for a bolt stretching dynamic yielding support. The black dot-dash line represents the average response for a bolt ploughing or sliding dynamic yielding support. The $23 \mathrm{~mm}$ bolt is close to the Yielding Support from bolt stretching. With similar dynamic response, the bolt can be made to be statically stiff or statically yielding. The $17.2 \mathrm{~mm}$ bolt is a lower strength dynamic response but less displacement than the typical yielding support from bolt ploughing/sliding. Again, with similar dynamic response, the bolt can be made to be statically stiff or statically yielding. 
DYNAMIC TESTING RESULTS

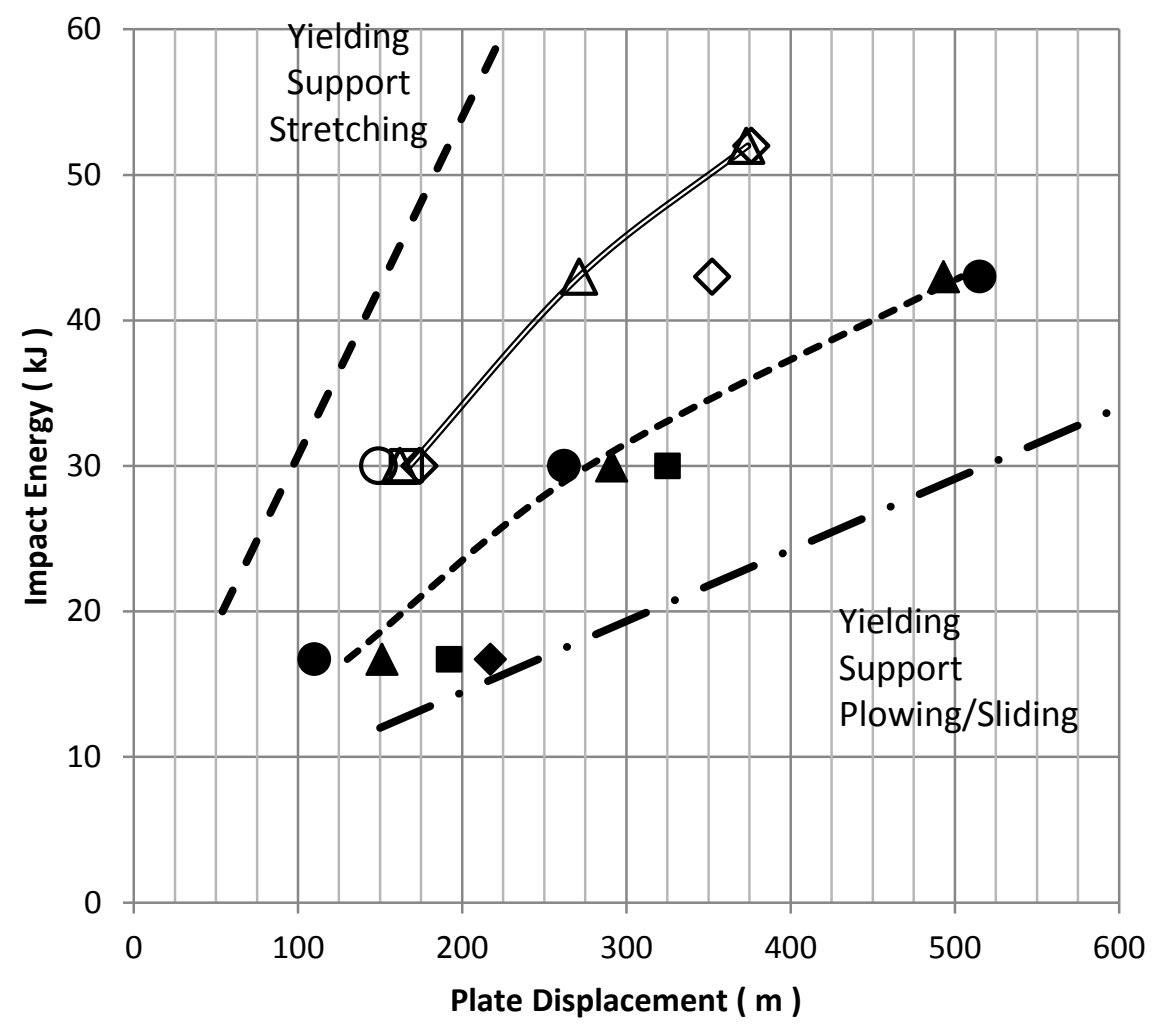

Upset

Diameter

and Static

Coating Result

- U1 C1 - Yielding

- U2 C1

$\Delta \quad$ U2 C2 - Stiff

- U2 C3 - Stiff/Break

$\diamond$ U3 C2 - Yielding

—-U3 C3 - Stiff/Break

$\Delta$ U4 C2 - Stiff/Break

O U4 C3 - Stiff/Break

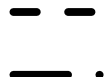

- $17.2 \mathrm{~mm}$

ऍ $23 \mathrm{~mm}$

\section{Figure 12 Dynamic testing results}

\section{References}

ASTM D7401-08 (2008) Standard Test Methods for Laboratory Determination Of Rock Anchor Capacities By Pull And Drop Tests, ASTM International.

Doucet, C. and Voyzelle, B. (2012) Technical Information Data Sheets, Review Completed May 29, 2012.

WIPO (2011) World Intellectual Property Organization, Patent Publication No. WO201102879 on Yielding Bolt and Assembly, viewed 24 November 2011, http://www.wipo.int/patentscope/search/en/WO2011028790.

$\mathrm{Wu}, \mathrm{Y}$. and Oldsen, J. (2010) Development of a new yielding rock support - Yield-Lok bolt, in Proceedings 44th U.S. Rock Mechanics Symposium, 27-30 June, 2010, Salt Lake City, Utah. 
